\title{
Management of Esophageal Perforation in Adults
}

\author{
Lileswar Kaman a, d, Javid Iqbala , Byju Kundil ${ }^{\text {, }}$, Rakesh Kochhar ${ }^{\mathrm{c}}$
}

\begin{abstract}
Perforation of esophagus in the adult is a very morbid condition with high morbidity and mortality. The ideal treatment is controversial. The main causes for esophageal perforation in adults are iatrogenic, traumatic, spontaneous and foreign bodies. The morbidity and mortality rate is directly related to the delay in diagnosis and initiation of optimum treatment. The reported mortality from treated esophageal perforation is $10 \%$ to $25 \%$, when therapy is initiated within 24 hours of perforation, but it could rise up to $40 \%$ to $60 \%$ when the treatment is delayed beyond 48 hours. Primary closure of the perforation site and wide drainage of the mediastinum is recommended if perforation is detected in less than 24 hours. Treatment option for delayed or missed rupture of esophagus is not very clear and is controversial. Recently a substantial number of patients with esophageal perforation are being managed by nonoperative measures. Patients with small perforations and minimal extraesophageal involvement may be better managed by nonoperative treatment Major prognostic factors determining mortality are the etiology and site of the injury, the presence of underlying esophageal pathology, the delay in diagnosis and the method of treatment. For optimum outcome for management of esophageal perforations in adults a multidisciplinary approach is needed.
\end{abstract}

Keywords: Esophagus; Esophageal perforations; Esophagectomy; Boerhaave's syndrome

Manuscript accepted for publication December 6, 2010

${ }^{a}$ Department of General Surgery, Post Graduate Institute of Medical Education and Research, Chandigarh, India

${ }^{\mathrm{b}}$ Department of GI Surgery, Lakeshore Hospital, Cochin, Kerala, India

${ }^{c}$ Department of Gastroenterology, Post Graduate Institute of Medical

Education and Research, Chandigarh, India

dCorresponding author: kamanlil@yahoo.com

doi:10.4021/gr263w

\section{Introduction}

Esophageal perforation is a surgical emergency associated with high morbidity and mortality. Consensus regarding the appropriate management of this life-threatening condition is lacking. The reported mortality from treated esophageal perforation is $10 \%$ to $25 \%$, when therapy is initiated within 24 hours of perforation and it is $40 \%$ to $60 \%$ when the treatment is delayed [1-6]. The reason for this manifold increase in mortality is due to the unique anatomical configuration and location of the esophagus, which allows bacteria and digestive enzymes easy access to the mediastinum, leading to the development of severe mediastinitis, empyema, sepsis, and multiple organ dysfunction syndromes [7]. Moreover, the rarity of this condition and its nonspecific presentations lead to diagnostic and treatment delay in more than $50 \%$ of perforations [6]. Etiological factors are iatrogenic, traumatic, spontaneous and foreign bodies [7-10]. Primary closure and wide drainage of the mediastinum is the treatment of choice if detected in less than 24 hours [1-17]. Treatment option for delayed or missed rupture is not clear and is controversial [18-37]. Major prognostic factors are the cause and site of the injury, the presence of underlying esophageal pathology, the delay in diagnosis and the method of treatment [1-14].

\section{Etiology}

Iatrogenic perforation is the leading cause of esophageal perforations [1-8] (Table 1). Iatrogenic causes account for around $70 \%$ of esophageal perforations $[1,3,6,8]$. Endoscopic procedures are the most common cause of iatrogenic esophageal perforation. The reported risk for diagnostic esophagogastrodudenoscopy is $0.03 \%$. The risk of perforation increases when therapeutic procedures are performed at the time of endoscopy. The reported risk for perforation is $0.5 \%$ in esophageal dilation, $1.7 \%$ in esophageal dilation for achalasia, $1-6 \%$ for endoscopic variceal sclerotherapy, $5 \%$ for endoscopic laser therapy, $4.6 \%$ for photodynamic therapy and esophageal stent placement carries a risk of $5-25 \%$ [1-8]. In diagnostic endoscopy the cervical esophagus at the cricopharynx is the most common site for injury $[1,3,6]$. 
Table 1. Etiology of Esophageal Perforations

Endoscopic
- Diagnostic endoscopy
- Endoscopic biopsy
- Endoscopic dilatations
- Variceal Sclerotherapy
- Endoscopic laser therapy
- Endoscopic Photodynamic therapy
- Endoscopic Stent Placement
Nasogastric tube placement
Endotracheal intubations

Transesophageal echocardiography

Minitracheostomy

Foreign bodies-

Bones, dentures, button batteries

Trauma

- Blunt

- Penetrating

- $\quad$ Sword swallowing

Spontaneous or Boerhaave's syndrome

Caustic agents

- $\quad$ Acid and alkali

Severe Reflux and Mallory-Weiss tear

Infective causes

- Candida

- Herpes

- Syphilis

- Tuberculosis

- Immunodeficiency status

Non esophageal surgery -

Mediastinal and cervical -Thyroid, Lung, spine and mediastinal tumors

Malignancy of esophagus, Lung and other mediastinal structures

Endoscope causes perforation by either piercing or shearing near the pharyngoesophageal junction where the wall is weakest. During endoscopic biopsy and therapeutic endoscopy mid and distal esophageal perforations occur $[1,3,6$, 8]. Other causes of iatrogenic esophageal perforation include nasogastric tube insertion, difficult endotracheal intubation, minitracheostomy, surgery of the mediastinal organs including resection of lung cancer, blind dissection of the abdominal esophagus, operations on the cervical spine, thyroidectomy, and palliative intubation, stenting, or laser treatment of esophageal tumors [1-8]. Another interesting reported cause of esophageal perforation is transesophageal echo, which is associated with $0.1 \%$ to $0.3 \%$ perforation rate [38].

Esophageal perforations may occur due to trauma to the chest and upper abdomen [10-12, 39]. Penetrating injury may be due to gunshot or stab wound. Blunt trauma is also a major cause of esophageal perforation [12, 39]. Motor vehicle accident causes blunt esophageal perforations and $82 \%$ of these occur in the cervical and upper thoracic esophagus, perhaps because that is just distal to where the esophagus is fixed [39].

Boerhaave's syndrome or spontaneous perforation of esophagus is induced by straining and vomiting [13-15]. There is generally a history of resisting vomiting, but it has also been reported after weight lifting, coughing and childbirth. Ruptures usually occur in the left posterior aspect of the lower esophagus and are more frequent in males [13-15]. The delay in diagnosis and treatment in this condition is associated with poor survival [13-15, 40-42]. Foreign bodies, usually bones: chicken, fish, pigeon, rabbit and pork causes esophageal perforations $[1,8,12,16,27,43]$. They puncture the esophageal wall directly or can cause perforation by pressure necrosis ultimately leading to perforation. Dentures are also important cause of esophageal perforations $[8,16,27$, 43]. Other notable foreign bodies include button batteries, which require urgent retrieval because of their alkaline contents $[43,44]$. Caustic agents (both acid and alkali) cause injury and perforation of esophagus [43-48]. Alkaline material accounts for most cases of caustic ingestion in the developed world, whereas acid ingestion appears to be more common in developing countries, like India, where hydrochloric acid and sulfuric acid are easily accessible [47, 48]. Esophageal perforation due to blister wrapped tablets has been reported [49]. Other conditions like severe reflux and candida, herpetic and immunodeficiency infections and malignancy can also cause perforations. Mallory-Weiss tear can perforate esophagus due to rapid increases in intragastric pressure against a closed pylorus [12].

\section{Presenting features}

Presenting features depend on the site of the perforations, the etiological factors and time of presentations $[1,2,6,8,12]$. Pain is present in about $80 \%$ of patients, usually referring directly to the site of perforation $[1,2,16]$. Other symptoms are vomiting, hematemesis, dysphagia, tachypnea, cough and fever $[1,2,8,12]$. The typical presentation of spontaneous esophageal rupture is severe vomiting or retching followed by acute, severe chest or epigastric pain [13 -15]. The presence of pain in the neck, upper back, chest, or abdomen, dysphagia, odynophagia, dysphonia or dyspnea and fever following esophageal instrumentation should raise suspicion for perforation of the esophagus $[1-3,6,12,16]$. The history of foreign body or caustic agent ingestion followed by the above symptoms indicates esophageal perforation until proven otherwise. The signs for esophageal perforations are 
mostly nonspecific. But most of the time there is tachycardia; hypotension, shock, fever, subcutaneous emphysema, pneumothorax and hemothorax are present $[1-8,12,16]$. Subcutaneous emphysema is present in up to $60 \%$ of perforations but requires at least an hour to develop after the initial injury $[8,12,16]$. In spontaneous esophageal perforation the classical Mackler triad, consisting of vomiting, chest pain, and subcutaneous emphysema is present in about $50 \%$ of cases [13-15, 40-42]. In cervical perforation there is pain in the neck with neck stiffness due to esophageal attachment to the prevertebral fascia limiting spread of oropharyngeal soilage [1]. Surgical emphysema is also typically seen in case of cervical perforation. In case of thoracic perforation there is severe chest pain with features of mediastinitis and pneumo or hemothorax. In lower esophageal perforations there may be signs of peritonitis. Abdominal pain may radiate to back if there is collection in the lesser sac. These symptoms vary according to the etiology and the time of presentations. In cases of delayed presentation, patients may be critically ill and may present with gross sepsis and multiple organ dysfunction syndromes $[8,13-15]$.

\section{Diagnosis}

The essential attribute of the diagnostic approach to esophageal rupture is the maintenance of a high index of suspicion. Any patient who presents with pain or fever following forceful vomiting, esophageal instrumentation, or chest trauma should be aggressively evaluated, with the aim of ruling out perforation of the esophagus [1-8]. The signs and symptoms of early esophageal perforations may be very subtle and can be misleading. If cervical esophageal perforation is suspected, a lateral neck X-ray may demonstrate air in the prevertebral facial planes. In thoracic or intra-abdominal esophageal perforation, posterior and lateral chest radiographs, and upright abdominal series should be obtained [50,51]. Pneumomediastinum, subcutaneous emphysema, mediastinal widening, or a mediastinal air-fluid level may be seen in the chest $\mathrm{x}$-ray $[50,52]$. Pneumothorax may be present in up to $77 \%$ of the time and it occurs when there is violation of the mediastinal pleura in $70 \%$ of the time it is on the left, $20 \%$ on the right and $10 \%$ bilaterally $[50,52]$. Hydropneumothorax on the left is seen in patients with distal third esophageal perforations [53]. Once there is suspicion of esophageal perforation in the chest x-ray, a contrast esophagogram should be performed immediately [1-3]. There is controversy regarding use of water-soluble contrast agent (Gastrografin) because of its moderate sensitivity $(60-70 \%)$ [1-8]. Negative scan always does not exclude perforation, especially in the cervical esophagus because of the rapid transit of the thin contrast. Contrast esophagography using a water-soluble agent initially followed by a barium study if the initial result is negative. It represents the most reliable test for dem- onstrating the presence and location of a perforation. Dilute barium study may reveal the primary area of leakage and determines whether the perforation is confined to the mediastinum or communicates freely with the pleural or peritoneal cavities, which has got significant bearing on the subsequent management. There is a concern regarding severe inflammatory response in tissues, most notably a mediastinitis. A contrast-enhanced CT scan of the chest should be performed if there is problem in getting a contrast esophagogram or in case of negative study despite high clinical suspicion or to rule out alternative diagnosis $[54,55]$. Perforation may be suggested by mediastinal air, extravasated luminal contrast, periesophageal fluid collections, pleural effusions, or actual communication of an air-filed esophagus with an adjacent mediastinal air-fluid collection $[54,55]$. If a perforation is suspected during an endoscopic procedure, careful inspection of the esophagus without air insufflation is warranted before taking out the endoscope but is not recommended as a primary diagnostic procedure as insufflated air can cause further dissection of the perforation $[1-8,56]$. The other diagnostic modalities that may be used are MRI to rule out dissection of aorta [52]. Ventilation perfusion (V/Q) scan and CT scanning of the lungs to rule out pulmonary embolism $[52,55]$. ECG may exclude myocardial infarction or associated cardiac abnormalities.

\section{Management}

The appropriate management of esophageal perforation is a controversial issue $[1-8,12,16]$ (Table 2). Early diagnosis, in less than 24 hours is vital to good outcomes. The mortality is $10 \%$ with early diagnosis and appropriate treatment but the mortality is up to $50 \%$ with late diagnosis $[1-8,12,16-$ 18]. Most of the iatrogenic perforations often noted immedi-

Table 2. Diagnosis of Esophageal Perforations

\begin{aligned} & \hline History \\ & Clinical examinations \\ & Radiology Plain \\ & - $\quad$ Neck X-ray lateral view \\ &$-\quad$ Chest X-ray PA view \\ &$-\quad$ Abdominal X-ray erect \\ & Radiology Contrast \\ & - $\quad$ Gastrografin study(water soluble contrast) \\ &$-\quad$ Thin barium swallow study \\ &$-\quad$ CT scan of chest and abdomen with oral contrast \\ & - MRI chest and abdomen \\ & ECG \\ & \hline\end{aligned}


ately during endoscopic instrumentation, results in improved outcome $[3,17,24,31,36,37]$. The choice of treatment depends on the etiology, site of perforation, general physical condition of the patient and the extent of contamination as determined by radiology $[1-8,12,14,16,18,57,58]$. The treatment also depends on the status of the esophagus: perforation in a healthy esophagus and perforation with a preexisting underlying intrinsic esophageal disease causing distal obstruction need different approach [8, 28, 30]. Nonoperative treatment is appropriate when esophageal perforation is encountered late $[1-5,36,37]$. Surgery is the mainstay of treatment, but recently there has been a trend toward more non operative management [1-8, 36, 37, 59-61]. Treatment should be started as early as possible and that should include intravenous fluid, nothing by mouth, broad spectrum antibiotics, narcotic analgesics, total parenteral nutrition, and decision regarding surgical closure versus non operative management $[1-8,12,14,16,17]$. Patients with hemodynamic instability or any degree of airway compromise should undergo treatment in an intensive care setting with complete resuscitative facilities, including emergency airway equipment and artificial respiratory support.

\section{Nonoperative Management}

Recent evidence indicates that a substantial number of patients with esophageal perforation can be managed by nonoperative measures [1-5, 8, 36, 37, 59-62]. Patients with small well-defined tears and minimal extraesophageal involvement may be better managed by nonoperative treatment [59, 60]. The criteria for nonoperative management was initially described by Cameron et al in 1979 and modified by Altorjay in 1997 [59, 60]. These include: early diagnosis or delayed diagnosis with contained leak, perforation not in the abdomen, contained perforation in the mediastinum, content of the perforation draining back to the esophagus, perforation does not involve neoplasm or obstruction of the esophagus, absence of sepsis, presence of experienced thoracic surgeon and contrast imaging in the hospital [59, 60]. Most of the recent iatrogenic perforations or late postemetic esophageal perforation may be managed by nonoperative management $[3,7,24,31,36,37]$. Many authors believe that if treatment is delayed for more than 24 hours after the perforation, the modality of treatment really does not influence the outcome and most cases can be managed by nonoperative treatment [31, 36, 37]. Nonoperative treatment includes large bore intravenous access, supplemental oxygen and cardiopulmonary monitoring in a critical care setting. Patient should be kept nil per oral and should have a nasogastric tube placed to clear gastric contents and limit further contamination. Broad spectrum intravenous antibiotics should be instituted as early as possible and should be given for minimum of $7-10$ days. Adequate analgesia including narcotic analgesia should be provided to control pain and discomfort, but it should be used judiciously in hypotensive patients. Intercostal chest tube should be placed to decompress the chest as and when necessary. Total parenteral nutrition should be instituted if a prolonged course is anticipated. Percutaneous gastrostomy may also be considered. Recently endoscopic placements of removable covered esophageal stents have been described in the care of patients with esophageal perforation with excellent results [63-67]. By using removable Polyflex esophageal stents both primary and secondary esophageal leaks are being treated with reduced hospital stay, fewer adjunctive procedures and early resumption of oral diet $[23,65,66]$. Stent migration is a problem and must be recognized because it may cause gastric outlet obstruction after lodgment at the pylorus. Fibrin sealant has also been used in treatment of esophageal perforation [25]. Successful endoscopic closure of esophageal perforation with metallic clips has been reported for perforations associated with instrumentation, foreign body ingestion and Boerhaave's syndrome. This mode of treatment is suitable only for selected patients with small $(\leq 1.5 \mathrm{~cm})$ clean perforation and minimal symptoms of infection. Although the length of time between the occurrence and the diagnosis of perforation is an important prognostic factor, recent reports advocated clipping of mature perforation in special circumstances $[68,69]$. Repeated and regular contrast study should be utilized to ascertain the progress of the treatment. Early consultation and active involvement of experienced esophageal or thoracic surgeon is a must during the nonoperative conservative management. Shifting the patient may be required to a tertiary care facility if these facilities are not available at the presenting hospital. Any signs and symptoms of sepsis during the course of nonoperative management warrant immediate surgical intervention. Respiratory complications like pneumothorax, mediastinal emphysema, and respiratory failure are also indications for surgical intervention $[59,60]$. The mortality for nonoperative management of esophageal perforations is 20 to $38 \%$ [1-8, $11,12]$. But in some center with carefully selected patients the reported mortality from nonoperative management has been zero [3, 13] (Table 3).

\section{Operative Management}

Operative management is the main modality for treatment of esophageal perforation till today [61]. In the last 2 decades, the advances in anesthesia, postoperative care, total parenteral nutrition and powerful and selective antibiotics have caused substantial improvements in the outcome of esophageal perforation with surgical treatment [1-8] . There is no clear cut recommendation for indication of surgery but it includes: early postemetic perforation, hemodynamic instability, intra-abdominal perforation, extravasations of contrast into adjacent body cavities and presence of underlying malig- 
Table 3. Treatment Options for Esophageal Perforations

\begin{tabular}{|c|l|}
\hline Operative & Non operative \\
\hline Primary closure & $\begin{array}{l}\text { Conservative management } \\
\text { Primary closure with buttressing of repair with }\end{array}$ \\
$-\quad$ Pleural flap & $\begin{array}{l}\text { Fibrin glue applications } \\
\text { Endoclip application }\end{array}$ \\
$-\quad$ Pericardial fat pad & \\
$-\quad$ Omentum onlay graft & \\
$-\quad$ Rhomboid muscle & \\
- Latissimus dorsi muscle $\quad$ Intercostal muscle & \\
T-tube drainage & \\
Drainage only & \\
Esophagectomy with & \\
- Immediate reconstruction & \\
- Delayed reconstruction & \\
Exclusion and diversion & \\
\hline
\end{tabular}

nancy, obstruction or stricture in the region of the perforation and surgically fit patient $[1-8,12,14,16]$. All patients with esophageal perforation should undergo a planned intervention with an adequate period of resuscitation, and it should be done by the most experienced and a complete operating team in an elective list if possible $[16,17,37]$. The surgical procedure selected depends on surgeon's experience, etiology of the perforation, time from injury to diagnosis and the site of perforation. Despite adequate surgical repair, continued esophageal leakage occurs in $30 \%$ of patients and $40 \%$ of these patients will require additional procedures there by increasing the morbidity and duration of hospitalization [3537]. Different procedures described for esophageal perforation include primary repair with or without reinforcement [1-12], simple drainage of the thoracic cavity [21], exclusion diversion operation [22], and single stage esophageal resection with or without primary reconstruction $[7,8,26$ 30]. Thoracoscopic repair using minimally invasive surgery is also described in the literature [70]. The fact that many procedures have been described in the literature is indicative that not a single surgical procedure could be considered a gold standard for the treatment of esophageal perforation [8]. Regarding the surgical procedure for delayed or missed rupture of esophagus is not very clear and still controversial. Preoperative preparation includes aggressive fluid resuscitation, control of sepsis by broad spectrum antibiotics and nasogastric intubation for gastric decompression. For early perforation the site of perforation and the status of the esophagus are important factors in deciding the type of surgery. Management of perforation in the healthy esophagus is dif- ferent from perforation in a diseased or obstructed esophagus [8]. Resection of the esophagus is indicated in case of perforation in a diseased esophagus, whereas primary closure is indicated in perforation in a healthy esophagus. Perforations in the cervical esophagus are treated by primary closure and drainage of the neck. Upper thoracic esophageal perforations are approached by a right thoracotomy and left thoracotomy for the lower third. Lesions at the esophagogastric junction are approached by left thoracotomy or upper midline laparotomy. As a general principle all perforations require wide mediastinal drainage by opening the parietal pleura in its entire length of the esophagus [1-8]. Necrotic nonviable and grossly contaminated tissue in the mediastinum and the parietal pleura must be debrided. The esophagus and often the esophagogastric junction must be dissected completely to identify the site of perforation and mobilize the esophagus for a tension-free repair [1-8]. Whenever it is possible, the esophageal defect should be closed by primary suture repair, preferably in 2-layer closure of mucosa and muscularis. If it is not feasible, a single layer closure should be done. Some time it is not possible to do a direct closure because of friability of the tissue. In these cases, the esophageal tear closure should be done by using flaps over the defects [19, 58-65]. Various local tissues at the site of perforation have been used to buttress the primary repair $[71,78]$. Pleural flaps, omental flaps, intercostal muscle flaps and pericardial flaps have been described [72-76]. The diaphragm flap has also been used for buttressing the suture lines after primary closure 78 . Regardless of the technique chosen, the use of buttress techniques has definitely improved the outcome of the surgical 


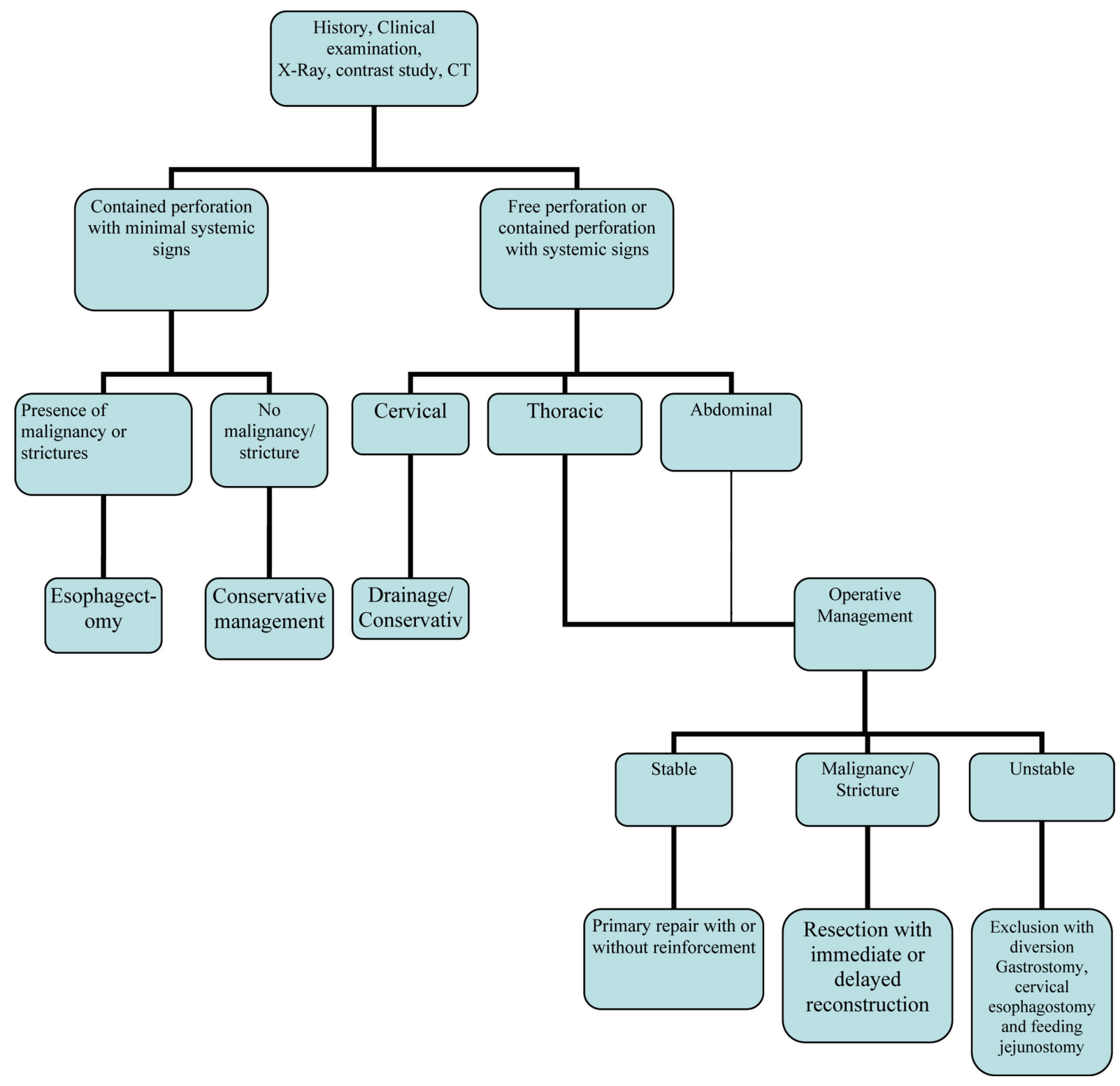

Figure 1. Management algorithm of esophageal perforation

treatment [71-78]. Reinforcement with vascularized tissue decreases the fistula formation (13\%) and mortality $(6 \%)$, compared to repair without reinforcement (39\%) and (25\%) $[72,73]$. All esophageal repairs should be drained by a large bore intercostal chest tube. A feeding jejunostomy should be always added for nutrition. Patients diagnosed with late perforations can usually be repaired primarily with reinforced muscle or pleura $[19,71,78]$. If primary repair is not possible because of the local tissue friability or there is severe mediastinitis, esophageal resection or exclusion and diversion should be considered [21, 22]. Exclusion and diversion comprises of cervical esophagostomy (diversion of the cervical esophagus and creating a salivary fistula), gastric decompression with a gastrostomy, esophagogastric junction stappling and jejunostomy [79]. Diversion procedures are relatively easy and quick procedures and should be performed early in patients with persistent sepsis despite initial surgical management, stenting as the initial step in patients unfit for a thoracotomy [79]. Drainage alone has been described for treatment of esophageal perforation, but it is still controversial [1]. Earlier reports suggest that drainage alone with other measure has got a worse outcome [59,60]. Modified T-tube repair of delayed esophageal perforation results in a low mortality rate similar to that seen with acute perfora- 
tions [80]. The use of esophagectomy for perforations was reported in the 1950s [81]. Patients with perforation of the esophagus in a diseased esophagus are best treated by resection $[8,82]$. Esophageal resection with or without immediate reconstruction should be considered for perforations in patients with megaesophagus, carcinoma, caustic ingestion, stenosis or severe undilatable reflux strictures. If the underlying pathologic process is esophageal carcinoma, resection and immediate reconstruction are indicated if the lesion is otherwise resectable [7, 8, 26-30]. Postoperative care should be in critical care setting with haemodynamic monitoring, cardiac and respiratory support. Broad spectrum antibiotic should be continued for 7 - 10 days. Nasogastric decompression of the stomach until resolution of the postoperative ileus, after which enteral feeding should be started through a jejunostomy tube. Contrast study should be obtained on the 5 th postoperative day to document the integrity of the repair. Long-term surveillance for stricture formation, reflux or carcinoma is also recommended (Table 3).

\section{Prognosis}

In a recent review the overall mortality associated with esophageal perforation in 726 patients from series between 1990 and 2003 was 18\% [83]. The mortality rate has not changed significantly compared to a mortality of $22 \%$ reported in a similar review of case series between 1980 and 1990 by Jones and Ginsberg [1]. Major prognostic factors determining mortality are the cause and location of the injury, the presence of underlying esophageal pathology, the delay in diagnosis and the method of treatment. Spontaneous esophageal perforation was associated with highest mortality of $36 \%$ ( $0 \%$ to $72 \%)$, followed by iatrogenic perforation with a mortality of $19 \%$ ( $7 \%$ to $33 \%)$, and traumatic perforation with a mortality of $7 \%(0 \%$ to $33 \%)[1-8,16-37$, $83,84]$. In relation to the location of perforation cervical esophageal perforations have better prognosis with a mortality of $6 \%(0 \%$ to $16 \%)$, whereas thoracic and abdominal perforations were associated with a mortality of $27 \%(0 \%$ to $44 \%$ ), and $21 \%$ ( $0 \%$ to $43 \%)$, respectively [1-8, 16-37]. The interval from perforation to initiation of treatment is a crucial determinant of outcome after esophageal perforation. The overall reported mortality of esophageal perforation with treatment delayed by 24 hours or more was $27 \%(0 \%$ to $46 \%)$ compared to $14 \%(0 \%$ to $28 \%)$ when treatment was initiated within 24 hours [1-8]. Amudhan et al [56] reported overall mortality $6.2 \%$ in their study group and none of the patients treated within $24 \mathrm{hrs}$ died and they concluded that early diagnosis decreases mortality and hospital stay in esophageal perforation. Eroglu et al [85] reported overall mortality of (11.4\%); mortality among patients treated within $24 \mathrm{hrs}$ of sustaining the injury was substantially less than among those for whom diagnosis and treatment were delayed $(3 \%$ and $36.4 \%$, respectively). Cervical esophageal perforations resulted in lower mortality rates than thoracic or abdominal perforations. Patients treated by surgical management had less mortality then non operative management [85]. Patients underwent primary repair of esophageal perforation has better outcome then in patients with esophageal perforation repaired over a drain.

The mortality rate was 3\% in primary repair group compared with $18 \%$ in patients with esophageal perforation repaired over a drain [61]. Recent literature favors primary repair as the best surgical approach with consistently low mortality ranging from $3 \%$ to $13 \%$ [86-88].

In conclusion, esophageal perforation in adults is a highly morbid condition with high mortality. Mortality rates mainly depend on time of presentation and etiology of perforation. The overall mortality is $20 \%$, while iatrogenic instrumental perforation has a lower mortality of $10 \%$, and postemetic perforation has a higher reported mortality rate of $60-70 \%$. The reported mortality from treated esophageal perforation is $10 \%$ to $25 \%$, when therapy is initiated within 24 hours of perforation, but it could rise up to $40 \%$ to $60 \%$ when the treatment is delayed beyond 48 hours. The mortality rates are also higher in patients with thoracic and abdominal rupture and underlying esophageal disease like malignancy and benign stricture. For optimum treatment outcome an algorithm for management is suggested (Fig. 1).

\section{References}

1. Jones WG, 2nd, Ginsberg RJ. Esophageal perforation: a continuing challenge. Ann Thorac Surg 1992;53(3):534543.

2. Skinner DB, Little AG, DeMeester TR. Management of esophageal perforation. Am J Surg 1980;139(6):760764.

3. Sarr MG, Pemberton JH, Payne WS. Management of instrumental perforations of the esophagus. J Thorac Cardiovasc Surg 1982;84(2):211-218.

4. Michel L, Grillo HC, Malt RA. Operative and nonoperative management of esophageal perforations. Ann Surg 1981;194(1):57-63.

5. Brewer LA, 3rd, Carter R, Mulder GA, Stiles QR. Options in the management of perforations of the esophagus. Am J Surg 1986;152(1):62-69.

6. Bladergroen MR, Lowe JE, Postlethwait RW. Diagnosis and recommended management of esophageal perforation and rupture. Ann Thorac Surg 1986;42(3):235-239.

7. Altorjay A, Kiss J, Voros A, Sziranyi E. The role of esophagectomy in the management of esophageal perforations. Ann Thorac Surg 1998;65(5):1433-1436.

8. Gupta NM, Kaman L. Personal management of 57 consecutive patients with esophageal perforation. Am J Surg 2004;187(1):58-63. 
9. Iannettoni MD, Vlessis AA, Whyte RI, Orringer MB. Functional outcome after surgical treatment of esophageal perforation. Ann Thorac Surg 1997;64(6):16061609; discussion 1609-1610.

10. English GM, Hsu SF, Edgar R, Gibson-Eccles M. Oesophageal trauma in patients with spinal cord injury. Paraplegia 1992;30(12):903-912.

11. Pass LJ, LeNarz LA, Schreiber JT, Estrera AS. Management of esophageal gunshot wounds. Ann Thorac Surg 1987;44(3):253-256.

12. Attar S, Hankins JR, Suter CM, Coughlin TR, Sequeira A, McLaughlin JS. Esophageal perforation: a therapeutic challenge. Ann Thorac Surg 1990;50(1):45-49; discussion 50-41.

13. Vial CM, Whyte RI. Boerhaave's syndrome: diagnosis and treatment. Surg Clin North Am 2005;85(3):515-524, ix.

14. Ochiai T, Hiranuma S, Takiguchi N, Ito K, Maruyama M, Nagahama T, Kawano T, et al. Treatment strategy for Boerhaave's syndrome. Dis Esophagus 2004;17(1):98103.

15. Nehra D, Beynon J, Pye JK. Spontaneous rupture of the oesophagus (Boerhaave's syndrome). Postgrad Med J 1993;69(809):214-216.

16. Goldstein LA, Thompson WR. Esophageal perforations: a 15 year experience. Am J Surg 1982;143(4):495-503.

17. Adamek HE, Jakobs R, Dorlars D, Martin WR, Kromer MU, Riemann JF. Management of esophageal perforations after therapeutic upper gastrointestinal endoscopy. Scand J Gastroenterol 1997;32(5):411-414.

18. Nesbitt JC, Sawyers JL. Surgical management of esophageal perforation. Am Surg 1987;53(4):183-191.

19. Richardson JD, Tobin GR. Closure of esophageal defects with muscle flaps. Arch Surg 1994;129(5):541547; discussion 547-548.

20. Salo JA, Isolauri JO, Heikkila LJ, Markkula HT, Heikkinen LO, Kivilaakso EO, Mattila SP. Management of delayed esophageal perforation with mediastinal sepsis. Esophagectomy or primary repair? J Thorac Cardiovasc Surg 1993;106(6):1088-1091.

21. Flynn AE, Verrier ED, Way LW, Thomas AN, Pellegrini CA. Esophageal perforation. Arch Surg 1989;124(10):1211-1214; discussion 1214-1215.

22. Urschel HC, Jr., Razzuk MA, Wood RE, Galbraith N, Pockey M, Paulson DL. Improved management of esophageal perforation: exclusion and diversion in continuity. Ann Surg 1974;179(5):587-591.

23. Morgan RA, Ellul JP, Denton ER, Glynos M, Mason RC, Adam A. Malignant esophageal fistulas and perforations: management with plastic-covered metallic endoprostheses. Radiology 1997;204(2):527-532.

24. Liedman B, Johnsson E, Lundell L. Treatment of iatrogenic perforations with covered stents in patients with oesophageal cancer. Eur J Surg 2001;167(9):672-674.
25. Harries K, Masoud A, Brown TH, Richards DG. Endoscopic placement of fibrin sealant as a treatment for a long-standing Boerhaave's fistula. Dis Esophagus 2004; 17(4):348-350.

26. Adam DJ, Thompson AM, Walker WS, Cameron EW. Oesophagogastrectomy for iatrogenic perforation of oesophageal and cardia carcinoma. Br J Surg 1996;83(10):1429-1432.

27. DeMeester TR. Perforation of the esophagus. Ann Thorac Surg 1986;42(3):231-232.

28. Orringer MB, Stirling MC. Esophagectomy for esophageal disruption. Ann Thorac Surg 1990;49(1):35-42; discussion 42-33.

29. Ozcelik C, Inci I, Ozgen G, Eren N. Near-total esophageal exclusion in the treatment of late-diagnosed esophageal perforation. Scand J Thorac Cardiovasc Surg 1994;28(2):91-93.

30. Gupta NM. Emergency transhiatal oesophagectomy for instrumental perforation of an obstructed thoracic oesophagus. Br J Surg 1996;83(7):1007-1009.

31. Ballesta-Lopez C, Vallet-Fernandez J, Catarci M, Bastida-Vila X, Nieto-Martinez B. Iatrogenic perforations of the esophagus. Int Surg 1993;78(1):28-31.

32. Borotto E, Gaudric M, Danel B, Samama J, Quartier G, Chaussade S, Couturier D. Risk factors of oesophageal perforation during pneumatic dilatation for achalasia. Gut 1996;39(1):9-12.

33. Chong CF. Esophageal rupture due to SengstakenBlakemore tube misplacement. World J Gastroenterol 2005;11(41):6563-6565.

34. Scheinin SA, Wells PR. Esophageal perforation in a sword swallower. Tex Heart Inst J 2001;28(1):65-68.

35. Bufkin BL, Miller JI, Jr., Mansour KA. Esophageal perforation: emphasis on management. Ann Thorac Surg 1996;61(5):1447-1451; discussion 1451-1442.

36. Richardson JD, Martin LF, Borzotta AP, Polk HC, Jr. Unifying concepts in treatment of esophageal leaks. Am J Surg 1985;149(1):157-162.

37. Brinster CJ, Singhal S, Lee L, Marshall MB, Kaiser LR, Kucharczuk JC. Evolving options in the management of esophageal perforation. Ann Thorac Surg 2004;77(4):1475-1483.

38. Kallmeyer IJ, Collard CD, Fox JA, Body SC, Shernan SK. The safety of intraoperative transesophageal echocardiography: a case series of 7200 cardiac surgical patients. Anesth Analg 2001;92(5):1126-1130.

39. Beal SL, Pottmeyer EW, Spisso JM. Esophageal perforation following external blunt trauma. J Trauma 1988;28(10):1425-1432.

40. Bobo WO, Billups WA, Hardy JD. Boerhaave's syndrome: a review of six cases of spontaneous rupture of the esophagus secondary to vomiting. Ann Thorac Surg 1969; 172:1034-38.

41. Walker WS, Cameron EW, Walbaum PR. Diagnosis 
and management of spontaneous transmural rupture of the oesophagus (Boerhaave's syndrome). Br J Surg 1985;72(3):204-207.

42. Henderson JA, Peloquin AJ. Boerhaave revisited: spontaneous esophageal perforation as a diagnostic masquerader. Am J Med 1989;86(5):559-567.

43. Nashef SA, Klein C, Martigne C, Velly JF, Couraud L. Foreign body perforation of the normal oesophagus. Eur J Cardiothorac Surg 1992;6(10):565-567.

44. Kirsh MM, Ritter F. Caustic ingestion and subsequent damage to the oropharyngeal and digestive passages. Ann Thorac Surg 1976;21(1):74-82.

45. Estrera A, Taylor W, Mills LJ, Platt MR. Corrosive burns of the esophagus and stomach: a recommendation for an aggressive surgical approach. Ann Thorac Surg 1986;41(3):276-283.

46. Anderson KD. Corrosive injury. In: Pearson FG, Deslauriers J, Ginsberg RJ, Hiebert CA, McKneally MF, Urschel HC Jr, editors. Esophageal surgery. New York: Churchill Livingstone Inc.; 1995:465-78.

47. Arevalo-Silva C, Eliashar R, Wohlgelernter J, Elidan J, Gross M. Ingestion of caustic substances: a 15 -year experience. Laryngoscope 2006;116(8):1422-1426.

48. Riffat F, Cheng A. Pediatric caustic ingestion: 50 consecutive cases and a review of the literature. Dis Esophagus 2009;22(1):89-94.

49. Gupta NM, Gupta V, Gupta R, Sudhakar V. Esophageal perforation caused by a blister-wrapped tablet. Asian Cardiovasc Thorac Ann 2002;10(1):87-88.

50. Okten I, Cangir AK, Ozdemir N, Kavukcu S, Akay H, Yavuzer S. Management of esophageal perforation. Surg Today 2001;31(1):36-39.

51. Han SY, McElvein RB, Aldrete JS, Tishler JM. Perforation of the esophagus: correlation of site and cause with plain film findings. AJR Am J Roentgenol 1985;145(3):537-540.

52. Rubesin SE, Levine MS. Radiologic diagnosis of gastrointestinal perforation. Radiol Clin North Am 2003;41(6):1095-1115, v.

53. Naclerio EA. The V sign in the diagnosis of spontaneous rupture of the esophagus (an early roentgen clue). Am J Surg 1957;93(2):291-298.

54. Maniatis V, Chryssikopoulos H, Roussakis A, Kalamara C, Kavadias S, Papadopoulos A, Andreou J, et al. Perforation of the alimentary tract: evaluation with computed tomography. Abdom Imaging 2000;25(4):373-379.

55. Backer CL, LoCicero J, 3rd, Hartz RS, Donaldson JS, Shields T. Computed tomography in patients with esophageal perforation. Chest 1990;98(5):1078-1080.

56. Pace F, Antinori S, Repici A. What is new in esophageal injury (infection, drug-induced, caustic, stricture, perforation)? Curr Opin Gastroenterol 2009;25(4):372-379.

57. Bhatia NL, Collins JM, Nguyen CC, Jaroszewski DE, Vikram HR, Charles JC. Esophageal perforation as a complication of esophagogastroduodenoscopy. J Hosp Med 2008;3(3):256-262.

58. McMahon MA, O'Kelly F, Lim KT, Ravi N, Reynolds JV. Endoscopic T-tube placement in the management of lye-induced esophageal perforation: Case report of a safe treatment strategy. Patient Saf Surg 2009;3(1):19.

59. Cameron JL, Kieffer RF, Hendrix TR, Mehigan DG, Baker RR. Selective nonoperative management of contained intrathoracic esophageal disruptions. Ann Thorac Surg 1979;27(5):404-408.

60. Altorjay A, Kiss J, Voros A, Bohak A. Nonoperative management of esophageal perforations. Is it justified? Ann Surg 1997;225(4):415-421.

61. Abbas G, Schuchert MJ, Pettiford BL, Pennathur A, Landreneau J, Luketich JD, Landreneau RJ. Contemporaneous management of esophageal perforation. Surgery 2009;146(4):749-755; discussion 755-746.

62. Griffin SM, Lamb PJ, Shenfine J, Richardson DL, Karat $\mathrm{D}$, Hayes N. Spontaneous rupture of the oesophagus. $\mathrm{Br}$ J Surg 2008;95(9):1115-1120.

63. Tuebergen D, Rijcken E, Mennigen R, Hopkins AM, Senninger N, Bruewer M. Treatment of thoracic esophageal anastomotic leaks and esophageal perforations with endoluminal stents: efficacy and current limitations. J Gastrointest Surg 2008;12(7):1168-1176.

64. Freeman RK, Van Woerkom JM, Ascioti AJ. Esophageal stent placement for the treatment of iatrogenic intrathoracic esophageal perforation. Ann Thorac Surg 2007;83(6):2003-2007; discussion 2007-2008.

65. White RE, Mungatana C, Topazian M. Expandable stents for iatrogenic perforation of esophageal malignancies. J Gastrointest Surg 2003;7(6):715-719; discussion 719-720.

66. Sarper A, Oz N, Cihangir C, Demircan A, Isin E. The efficacy of self-expanding metal stents for palliation of malignant esophageal strictures and fistulas. Eur J Cardiothorac Surg 2003;23(5):794-798.

67. Blocksom JM, Sugawa C, Tokioka S, Williams M. The Hemoclip: a novel approach to endoscopic therapy for esophageal perforation. Dig Dis Sci 2004;49(7-8):11361138.

68. Raymer GS, Sadana A, Campbell DB, Rowe WA. Endoscopic clip application as an adjunct to closure of mature esophageal perforation with fistulae. Clin Gastroenterol Hepatol 2003;1(1):44-50.

69. Abe N, Sugiyama M, Hashimoto Y, Itoh N, Nakaura H, Izumisato $\mathrm{Y}$, Matsuoka $\mathrm{H}$, et al. Endoscopic nasomediastinal drainage followed by clip application for treatment of delayed esophageal perforation with mediastinitis. Gastrointest Endosc 2001;54(5):646-648.

70. Kiel T, Ferzli G, McGinn J. The use of thoracoscopy in the treatment of iatrogenic esophageal perforations. Chest 1993;103(6):1905-1906.

71. Ayed AK, Al-Din HJ, Asfar SK. Reinforced primary re- 
pair of early distal oesophageal perforation. Eur J Surg 2000;166(12):938-941.

72. Gouge TH, Depan HJ, Spencer FC. Experience with the Grillo pleural wrap procedure in 18 patients with perforation of the thoracic esophagus. Ann Surg 1989;209(5):612-617; discussion 617-619.

73. Grillo HC, Wilkins EW, Jr. Esophageal repair following late diagnosis of intrathoracic perforation. Ann Thorac Surg 1975;20(4):387-399.

74. Dicks JR, Majeed AW, Stoddard CJ. Omental wrapping of perforated esophagus. Dis Esophagus 1998;11(4):276278.

75. Lucas AE, Snow N, Tobin GR, Flint LM, Jr. Use of the rhomboid major muscle flap for esophageal repair. Ann Thorac Surg 1982;33(6):619-623.

76. Millard AH. 'Spontaneous' perforation of the oesophagus treated by utilization of a pericardial flap. Br J Surg 1971;58(1):70-72.

77. Bardaxoglou E, Manganas D, Meunier B, Landen S, Maddern GJ, Campion JP, Launois B. New approach to surgical management of early esophageal thoracic perforation: primary suture repair reinforced with absorbable mesh and fibrin glue. World J Surg 1997;21(6):618-621.

78. Jara FM. Diaphragmatic pedicle flap for the treatment of Boerhaave's syndrome. J Thorac Cardiovasc Surg 1997; 78: 931-33.

79. Rohatgi A, Papanikitas J, Sutcliffe R, Forshaw M, Mason $\mathrm{R}$. The role of oesophageal diversion and exclusion in the management of oesophageal perforations. Int $\mathrm{J}$ Surg 2009;7(2):142-144.

80. Linden PA, Bueno R, Mentzer SJ, Zellos L, Lebenthal
A, Colson YL, Sugarbaker DJ, et al. Modified T-tube repair of delayed esophageal perforation results in a low mortality rate similar to that seen with acute perforations. Ann Thorac Surg 2007;83(3):1129-1133.

81. Johnson R, Schwegman C H, MacVaugh III. Early esophagogastrostomy in the treatment of iatrogenic perforation of the distal esophagostomy. J Thorac Cardiovasc Surg 1956; 32: 827-31.

82. Yeo CJ, Killemoe KD, Klein AS, et al. Treatment of instrument perforation of esophageal malignancy by transhiatal esophagectomy. Arch Surg 1998; 123:1016-18.

83. Amudhan A, Rajendran S, Raj VV, Rajarathinam G, Jyotibasu D, Ravichandran P, Jeswanth S, et al. Management of esophageal perforation: experience from a tertiary center in India. Dig Surg 2009;26(4):322-328.

84. Eroglu A, Turkyilmaz A, Aydin Y, Yekeler E, Karaoglanoglu N. Current management of esophageal perforation: 20 years experience. Dis Esophagus 2009;22(4):374380 .

85. Martinek J, Kovacova S, Nosek V, Verner T, Vasicek M, Spicak J. Successful endoscopic treatment (clipping) of esophageal perforation during balloon dilatation in a patient with achalasia. Endoscopy 2008;40 Suppl 2: E6162.

86. Wright C. Primary repair for delayed recognition of esophageal perforation. In Difficult Decision in Thoracic Surgery: An Evidence-Based Approach. New York: Springer; 2008:298-304.

87. Wu JT, Mattox KL, Wall MJ, Jr. Esophageal perforations: new perspectives and treatment paradigms. J Trauma 2007;63(5):1173-1184. 